\title{
ESTIMATIVA RÁPIDA PARTICIPATIVA COMO FERRAMENTA DE DIAGNÓSTICO NA ESTRATÉGIA SAÚDE DA FAMÍLIA ${ }^{1}$

\author{
Maria Elisabeth Kleba* \\ Tânia de Fátima Duarte** \\ Aline Romanini**** \\ Ivanete R. Althaus******
} \\ Denise Cazarotto Cigognini*****
}

\begin{abstract}
Resumo
A estimativa rápida constitui-se ferramenta apropriada ao planejamento estratégico situacional para equipes de Saúde da Família, possibilitando a análise da situação de saúde do território, considerando a perspectiva dos diferentes atores sociais envolvidos na construção da realidade local. $\mathrm{O}$ presente estudo apresenta dados coletados no município de Pinhalzinho, oeste de Santa Catarina, por meio do Sistema de Informações da Atenção Básica (SIAB), oficinas com crianças e adolescentes de escolas locais, grupos de gestantes, idosos, hipertensos e diabéticos, bem como entrevistas com 11 lideranças e observação em campo, buscando identificar problemas e potencialidades que influenciam a saúde. Agentes comunitárias participaram do processo por meio de oito oficinas, que resultaram na construção de mapas físicos contemplando situações de interesse para o diagnóstico de saúde. Os resultados foram organizados a partir das seguintes dimensões: a) composição e capacidade de agir da população; b) fatores que influenciam as condições de vida e de saúde da comunidade; c) existência, cobertura, acesso e aceitabilidade de serviços de saúde, ambientais e sociais; e d) políticas públicas favoráveis e controle social na saúde. A estimativa rápida promove maior participação da comunidade no planejamento, mas também a intersetorialidade, gerando maior diálogo entre envolvidos e favorecendo a definição de ações e estratégias de promoção da saúde.
\end{abstract}

Palavras-chave: Participação comunitária. Estratégia Saúde da Família. Promoção da saúde. Ação intersetorial. Diagnóstico da situação de saúde.

1 Este artigo é resultado de projeto aprovado pelo Curso de Enfermagem da Universidade Comunitária da Região de Chapecó (Unochapecó) em Edital do Programa Nacional de Reorientação da Formação Profissional em Saúde (Pró-Saúde 1) do Ministério da Saúde. Registra-se também agradecimento aos trabalhadores da saúde, em especial agentes comunitárias de saúde, gestores e lideranças do município de Pinhalzinho, pelas contribuições no desenvolvimento do Trabalho de Conclusão de Curso "Prática gerencial de enfermagem baseada na teoria de Imogene King: aplicação da estimativa rápida no planejamento em saúde coletiva”. * Doutora em Filosofia e Pós-Doutora em Enfermagem. Professora da Universidade Comunitária da Região de Chapecó. E-mail: lkleba@unochapeco.edu.br.

** Enfermeira. Hospital Vitória, Curitiba/PR. E-mail: tania_fd4@yahoo.com.br

**** Enfermeira. Secretaria Municipal da Saúde de Catanduvas/SC.E-mail: aliner@unochapeco.edu.br

***** Enfermeira. Clínica de Fisioterapia De Marco, Chapecó.E-mail: de_nise_le@hotmail.com

****** Enfermeira, Coordenadora da Atenção Básica e Coordenadora da Vigilância Epidemiológica da Secretaria Municipal da Saúde de Pinhalzinho/SC. E-mail: epidemiologia@pinhalzinho.sc.gov.br 


\section{Introdução}

Com a intenção de promover a consolidação dos princípios e diretrizes do Sistema Único de Saúde (SUS), tais como a universalidade de acesso, a integralidade e a resolutividade da assistência à saúde, o Ministério da Saúde criou, em 1994, o Programa Saúde da Família, atualmente conhecido como Estratégia Saúde da Família (ESF). A ESF atua com uma equipe multiprofissional que oferece serviços em um determinado território, com uma população adstrita definida, tendo como foco o estabelecimento de vínculos e a criação de laços de compromisso e de corresponsabilidade entre os profissionais de saúde e a população, com base nas necessidades e prioridades da comunidade (BRASIL, 2011).

O trabalho de equipe possibilita interação, compartilhamento de saberes e experiências e oportuniza a inclusão de diferentes abordagens no planejamento das ações de promoção, proteção e recuperação da saúde, frente aos problemas de saúde vivenciados pela comunidade. Nessa perspectiva, a Portaria Nacional da Atenção Básica (PNAB) enfatiza a necessidade de o serviço de saúde se organizar para acolher e escutar os problemas de saúde da população, de forma a oferecer respostas que possam resolver a grande maioria dos problemas e/ou minorar danos e sofrimentos ou se responsabilizar por essas respostas, quando ofertadas em outros espaços da rede de atenção (BRASIL, 2011).

A organização dos serviços de saúde tem, no entanto, grandes desafios quando consideramos a necessidade de superar a centralidade do modelo assistencial voltado à demanda espontânea, com ênfase ao atendimento de indivíduos em situações de adoecimento. Para Tesser et al (2011, p. 4301), a não valorização das questões sociais, políticas e culturais pelos profissionais da saúde constitui-se grave problema, uma vez que "a participação, a mobilização social e política e o 'empowerment' coletivo são necessários para a sustentabilidade e o aprofundamento da construção da ESF e do SUS”. Nessa perspectiva, Gurgel et al (2011) enfatizam a necessidade de os profissionais de saúde ressignificarem e redefinirem seu papel e suas práticas junto à comunidade, reconhecendo o diálogo, a autonomia e o empoderamento como dimensões essenciais do processo de trabalho em saúde.

A importância da participação social na identificação das necessidades da população é apontada como uma das 
responsabilidades da gestão municipal pelo Ministério da Saúde em suas orientações para o planejamento em saúde (BRASIL, 2009a; 2011). De acordo com essas orientações, o planejamento tem como principal finalidade garantir que o SUS responda, com qualidade, às demandas e necessidades de saúde, considerando seus determinantes e condicionantes, o que requer o envolvimento de todos os profissionais, bem como a promoção da participação social e a integração intra e intersetorial.

Apesar de ter avançado em nível local, em especial pela prerrogativa da elaboração do Plano de Saúde pelo gestor municipal, o planejamento ainda não tem sido uma prática comum junto aos serviços de saúde. Em seu estudo junto a equipes da ESF, Tesser et al (2011) concluíram que estas raramente realizavam um trabalho sistematizado de análise da realidade, com vistas a apoiar sua atuação. Os dados registrados no Sistema de Informações em Saúde eram coletados como obrigação burocrática, revelando o não reconhecimento da equipe de seu potencial para gerar informações e apoiar a tomada de decisões na priorização das intervenções mais coletivas.

A coleta de informação faz parte da primeira etapa do planejamento; é o processo de obtenção de dados primários e de sua sistematização, com o objetivo principal de descrever a problemática identificada, por meio das categorias escolhidas de forma explícita e com maior fidedignidade, com vistas a conduzir e facilitar o processo de tomada de decisão (GONDIM et al, 2008).

A análise situacional consiste no processo de identificação, formulação e priorização de problemas em uma determinada realidade. O objetivo da análise situacional é permitir a identificação dos problemas e orientar a definição das medidas a serem adotadas (BRASIL, 2009a).

Com o objetivo de contribuir à identificação e ao desenvolvimento de iniciativas que qualifiquem a tomada de decisões no processo de planejamento em saúde, o presente relato apresenta a dinâmica e os resultados do diagnóstico situacional realizado no território de abrangência de uma Unidade de Saúde do Município de Pinhalzinho/SC. O diagnóstico foi realizado por meio da técnica da estimativa rápida, como estratégia de implementação do primeiro momento do planejamento estratégico situacional (PES), a qual possibilita a análise da situação de saúde em determinado distrito sanitário, levando em conta a perspectiva 
dos diferentes atores sociais envolvidos na construção da realidade local. Assim, a partir das diversas perspectivas e modos de compreender e explicar a realidade, a depender da situação na qual o sujeito social está inserido, é possível dar a direção mais adequada e favorável ao desenvolvimento do planejamento em saúde (MATUS apud KURCGANT, 2005).

\section{Metodologia}

O estudo foi realizado tendo como referência uma das Unidades de Saúde do município de Pinhalzinho, situado na região oeste de Santa Catarina. Com uma população de 17.868 habitantes, esse município conta com seis equipes da Estratégia Saúde da Família (ESF), duas das quais atuam na área de abrangência da unidade acima referida. Tendo como estratégia de coleta de dados a técnica da estimativa rápida, o estudo envolveu diretamente 19 agentes comunitárias de saúde (ACS). A coordenação do processo contou com a participação de profissionais ligados ao setor da saúde e da assistência social do município, com supervisão da enfermeira coordenadora da unidade de saúde na qual a experiência foi desenvolvida.

A estimativa rápida é uma técnica que possibilita - em pouco tempo e com baixo custo - conhecer a situação de saúde vivenciada pela população em um determinado território, identificando e selecionando problemas considerados necessidades declaradas por atores sociais que pretendam transformar esses problemas, bem como potenciais que requerem investimentos para sua manutenção e/ou fortalecimento (DI VILLAROSA, 1993).

Seguindo as orientações de Di Villarosa (1993), a coleta dos dados foi realizada em três etapas, durante o segundo semestre de 2009 e o primeiro de 2010. Em um primeiro momento, foram reunidos dados relacionados ao perfil demográfico e epidemiológico da população,identificando-se, ainda, organizações e serviços existentes na comunidade. Em seguida, os dados foram sistematizados e distribuídos em mapas físicos, de forma a revelar situações de interesse para o diagnóstico de saúde, como distribuição e acessibilidade aos serviços existentes, concentração de grupos vulneráveis e áreas de risco, entre outros. Em um terceiro momento, ocorreu a observação em campo do território, realizada a partir de oficinas envolvendo crianças e adolescentes das duas escolas locais, grupos de gestantes, de hipertensos e diabéticos 
e de idosos, bem como entrevistas realizadas com 11 lideranças locais que permitiram ampliar e complementar as informações, garantindo a delimitação dos problemas e das potencialidades de acordo com o ponto de vista dos atores locais.

O envolvimento das agentes comunitárias de saúde foi mobilizado por meio de oito oficinas em um período de três meses, realizadas na câmara de vereadores do município, tendo como finalidade a construção dos mapas, a identificação e seleção das lideranças e dos grupos incluídos na pesquisa, bem como a definição dos problemas e das potencialidades relevantes em cada microárea do território analisado.

Os dados foram analisados a partir do referencial proposto por Acúrcio, Santos e Ferreira (1998), que propõem quatro dimensões para a leitura da situação de saúde de um determinado território, a saber: a primeira é constituída pela composição e pela capacidade de agir da população, incluindo número e características dos habitantes, grupos existentes e lideranças ativas na comunidade. A segunda identifica fatores que influenciam as condições de vida e de saúde, tais como ambiente físico (incluindo moradia, vias de acesso, poluição e saneamento), ambiente socioeconômico (escolaridade, ocupação, renda e atividades desenvolvidas na comunidade) e o perfil de morbidade e mortalidade. A terceira refere-se à existência, à cobertura, ao acesso e à aceitabilidade dos serviços de saúde, ambientais e sociais, incluindo abastecimento da água, destinação de dejetos como lixo e esgoto, existência de escolas, espaços e oportunidades de lazer e de convivência. A quarta dimensão relaciona-se às políticas públicas que revelam o comprometimento dos governantes e o envolvimento dos diferentes segmentos sociais em favor da saúde. Nesse nível são incluídos o conhecimento e a participação da comunidade no conselho municipal de saúde.

Finalizando o processo, o diagnóstico da situação de saúde foi apresentado à comunidade com ampla participação de lideranças, dos grupos envolvidos e de autoridades locais. A apresentação ocorreu em espaço junto à câmara de vereadores, tendo à frente profissionais do setor da saúde, em especial as agentes comunitárias de saúde, que validaram, dessa forma, os resultados encontrados no estudo.

Cabe salientar que o projeto foi aprovado pelo Comitê de Ética em Pesquisas da Unochapecó, sob o parecer № 260/09, obtendo-se autorização das instituições e o consentimento 

Conselho Nacional de Saúde/Ministério da Saúde (CONEP/ CNS/MS).

\section{Resultados e discussão}

\section{O mapa inteligente como ferramenta de diagnóstico da realidade}

A partir dos diálogos iniciais com autoridades locais, dirigentes e profissionais da área da saúde, foram acordadas agendas e atividades com as agentes comunitárias de saúde das duas equipes da ESF envolvidas no estudo. Os dois primeiros encontros tiveram como objetivo organizar as ações para o desenvolvimento do trabalho, enfatizando a importância do reconhecimento dos problemas e potencialidades da área de atuação da equipe de saúde da família. Como membros da equipe da ESF, as agentes comunitárias de saúde participam do reconhecimento da área de abrangência, contribuindo na identificação de grupos, famílias e indivíduos expostos a riscos, de forma a permitir a análise da situação de saúde, considerando as características sociais, econômicas, culturais, demográficas e epidemiológicas do território e a priorização das situações a serem acompanhadas no planejamento local (BRASIL, 2011).

Outro aspecto abordado nessa etapa foi à necessidade de utilizar ferramentas que viabilizassem a realização do diagnóstico situacional, previsto na PNAB (BRASIL, 2006; 2011) como uma das atribuições da equipe da ESF, sendo a construção do mapa vivo ou inteligente uma das ferramentas indicadas.

Para a construção do mapa inteligente foi providenciada uma cópia ampliada do mapa do território adstrito à unidade de saúde junto ao setor de planejamento da prefeitura, identificando-se que este incluía apenas os traçados das ruas relativas ao perímetro urbano. $\mathrm{O}$ traçado das estradas do perímetro rural desse território foi desenhado pelas ACS, de acordo com seu conhecimento sobre as comunidades envolvidas, complementando a cópia do mapa físico original.

Isso evidenciou a segmentação territorial existente no setor responsável pelo planejamento do município e a dificuldade de reconhecer na análise das condições de vida do território situações 
de ruptura e de continuidade na relação urbano-rural que possam apoiar a administração municipal na eleição de prioridades em vista de maior equidade social.

O mapa foi então dividido em microáreas, de acordo com a região territorial de atuação das agentes comunitárias de saúde, sendo na sequência definidos os símbolos que expressariam as informações obtidas sobre a realidade local, a partir da organização de uma legenda comum. A construção dos símbolos deu-se de forma dialogada e problematizada com o grupo, visando padronizar as representações (formas, tamanhos e cores) e facilitar a comunicação (que o mapa fosse compreendido por todos os interessados).

Como um primeiro exercício de reconhecimento do território, as agentes comunitárias de saúde desenharam sua microárea de forma livre, localizando residências e equipamentos sociais relevantes. Esse exercício revelou um bom conhecimento do território por parte das agentes, evidenciando o que estas consideravam importante ou não na comunidade. Foi necessário, a partir do exercício, redimensionar o recorte das microáreas, de forma a adequar o tamanho do mapa aos conteúdos a serem nele inseridos.

Com base na legenda previamente definida, foi iniciada a construção dos mapas por meio da identificação das ruas e estradas, coloridas de acordo com sua estrutura (asfalto, calçamento ou terra) e das residências (em bom estado, regular ou precário), junto às quais foram identificadas, com alfinetes coloridos morbidades, as condições de saneamento e outras condições de interesse, como a presença de animais, arborização etc. Instituições, estabelecimentos comerciais e outros equipamentos comunitários foram identificados no mapa com desenhos representativos (por exemplo: posto de saúde, escolas, igrejas, campo de futebol). À medida que as microáreas foram sendo constituídas, as agentes comunitárias de saúde puderam reconhecer vazios e aglomerados que demarcavam situações de risco e vulnerabilidade, com maior demanda de intervenção preventiva e de acompanhamento, mas também espaços que revelavam oportunidades para desenvolver ou fortalecer ações de promoção da saúde.

O mapa inteligente expressa o território como espaço de vida e de convivência, por isso um "território vivo", cuja realidade registrada é percebida e significada de forma peculiar pelas pessoas que o habitam e/ou ali trabalham. O mapa constitui-se, ainda, 
ferramenta de diagnóstico da saúde da comunidade, à medida que "descreve" esse território, permitindo o registro de dados significativos, de acordo com a percepção das pessoas interessadas (BORNSTEIN, STOTZ, 2008).

A assistência integral à saúde requer conhecimento da realidade das famílias, das características sociais, demográficas, epidemiológicas e situações de risco do território de atuação (MENDES, 1996). O território é resultado de uma acumulação de situações históricas, ambientais e sociais que promovem condições particulares para a produção de doenças. $\mathrm{O}$ reconhecimento desse território é um passo básico para a caracterização da população e de seus problemas de saúde, bem como para a avaliação do impacto dos serviços sobre os níveis de saúde dessa população (BARCELLOS et al apud GONDIM et al, 2008, p. 2).

Como estratégia prioritária do Ministério da Saúde, a ESF tem a territorialização e a adstrição da clientela como um de seus princípios fundamentais, sendo a família foco principal das ações preventivas e as organizações comunitárias parceiras em potencial na promoção da saúde (BRASIL, 2011).

No encerramento da atividade, as agentes comunitárias de saúde apresentaram o diagnóstico de saúde representado no mapa inteligente, ressaltando aspectos positivos e negativos de cada microárea e validando os resultados do estudo com a comunidade. Estavam presentes, nesse encontro, representantes das equipes da ESF, representantes do poder legislativo, gestores municipais da saúde, da assistência social e da educação, representantes das escolas, pastoral da criança, lideranças da comunidade, entre outros, os quais validaram os achados do estudo.

\section{Dimensões da realidade na perspectiva da promoção da saúde}

\section{Estrutura e Capacidade de Ação da População}

O município de Pinhalzinho contava em 2010 com uma população de 16.335 habitantes, $46 \%$ residentes na área do estudo, a qual abrange quatro bairros, 10 comunidades do interior, divididos em 19 microáreas. 83,37\% das famílias do município residiam na área urbana e 50,07\% da população era do sexo masculino. As famílias, em sua maioria, tinham descendência alemã e italiana (BRASIL, 2010). O comparativo dos dados do 
Censo Demográfico de 2000 e com as estimativas populacionais para 2009 demonstraram que Pinhalzinho apresentou, nesse período, uma taxa média de crescimento populacional na ordem de 2,7\% ao ano (BRASIL, 2010).

Seguindo tendência nacional, observa-se no município o aumento significativo da população idosa em relação ao total de residentes nos últimos 30 anos (Figura 1). Em 2010, 10,28\% da população tinha 60 anos ou mais, sendo que na área de abrangência do estudo essa taxa representava $11,44 \%$. No mesmo sentido, no Brasil 10,79\% e em Santa Catarina 10,51\% do total da população tinha 60 anos ou mais.

Figura 1: Percentual da população residente com 60 anos ou mais, por ano, Pinhalzinho, Chapecó, Santa Catarina, Brasil, 1980, 1990, 2000, 2010.

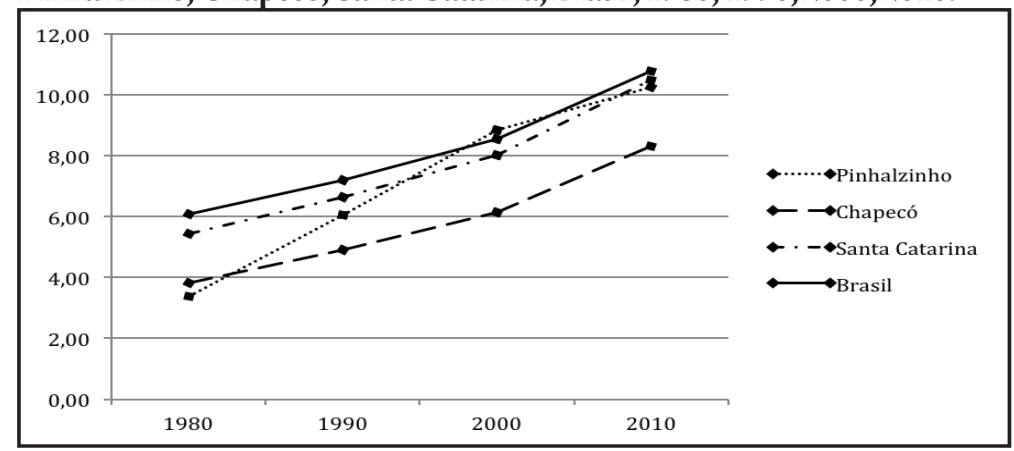

Fonte: BRASIL. Ministério da Saúde. Sistemas de Informação em Saúde. Dados demográficos, 2010.

Conforme dados do IBGE (BRASIL, 2009b), o crescimento da população idosa no Brasil é consequência do aumento da expectativa de vida ao nascer, também do avanço no campo da saúde e da redução da taxa de natalidade. Isso exige a definição de novas prioridades na área das políticas públicas, como a formação de recursos humanos para atendimento geriátrico e gerontológico e, em especial, políticas de promoção da saúde e de prevenção, as quais têm provado grande eficácia em todo o mundo na redução do declínio funcional entre idosos com consequente melhoria de sua qualidade de vida. Mendes e Loro (2002) também reforçam a importância de os profissionais estarem preparados para ações de promoção e proteção à saúde direcionadas a favorecer a qualidade de vida dessa faixa etária.

Como uma das atribuições fundamentais dos profissionais da atenção básica, a promoção da saúde deve ser pautada na realidade 
do território, integrando iniciativas e recursos existentes. Ações mais efetivas requerem o envolvimento dos indivíduos e grupos organizados do território na tomada de decisão, na definição de estratégias e na sua implementação, tendo em vista a melhoria das condições de vida e saúde. Central nesse processo é o aumento do poder e da autonomia das comunidades sobre seus próprios esforços e destino (BRASIL, 2002).

No território analisado, foram salientados pelos atores locais grupos religiosos, de idosos e de mulheres voluntárias, os quais desenvolvem atividades de apoio a grupos, famílias e pessoas não apenas em situação de vulnerabilidade, mas também no fortalecimento de iniciativas existentes. Percebeu-se baixo envolvimento de crianças e jovens em atividades comunitárias, em contraposição ao número significativo de grupos de idosos e de idosos participando dos grupos, a exemplo do grupo envolvido no estudo que contava com 160 sócios. Outro aspecto relevante é o número significativo de lideranças residentes na área rural reconhecidas pela equipe de saúde ( $27 \%$ do total identificado) na seleção para a coleta de informações, o que pode indicar maior relevância atribuída a esse papel pelas comunidades rurais.

Debatendo a noção de autonomia implicada no conceito de promoção da saúde, Haeser, Büchele e Brzozowski (2012) ressaltam que esta depende tanto do sujeito quanto da coletividade, uma vez que viver em sociedade requer dos indivíduos submeterse a um conjunto de regras, ainda que eles participem em sua criação. A autonomia depende de circunstâncias externas como cultura, economia, acesso à educação, à informação e de valores constituídos na sociedade, bem como da organização democrática da sociedade e das leis que regulam direitos e deveres individuais e coletivos.

\section{Fatores Socioambientais Favoráveis à Saúde na Comunidade}

Em geral, os entrevistados percebem como muito boas as condições das moradias, das ruas e estradas, apesar de reclamarem da iluminação insuficiente no período noturno nos bairros. Um dos grupos, bem como as crianças e os adolescentes da escola, destacaram como potencialidades da comunidade espaços de lazer, áreas verdes e praças, "lugares calmos e bonitos". No entanto, um aluno expressa o desejo de "[...] que tivesse mais áreas verdes nas praças, [com mais] lugares para os amigos, vizinhos e famílias 
se encontrarem". Esse depoimento corrobora com a visão de outros entrevistados, para os quais há espaços privilegiados no município que estão sendo ocupados para drogadição, o que provoca afastamento da comunidade e, consequentemente, perda de oportunidades de convivência e lazer saudável.

A Carta de Ottawa (BRASIL, 2002) salienta que toda estratégia de promoção da saúde deve incluir a proteção do meio ambiente e dos recursos naturais, criando-se ambientes favoráveis à vida e à convivência. Ambientes favoráveis e interação social são fundamentais na promoção da saúde, possibilitando momentos de descontração, lazer e comunicação entre as pessoas, desenvolvendo, dessa forma, sentimentos de pertencimento social, melhoria da autoestima e práticas solidárias na comunidade. Por outro lado, os espaços da área rural têm sido normalmente subaproveitados pela comunidade local. Esses espaços são potenciais áreas de lazer que podem ser valorizadas por meio de projetos envolvendo escoteiros, grupos praticantes de ciclismo, trilhas ecológicas e atividades escolares voltadas ao meio ambiente, contribuindo para a melhoria na interação da população urbana e rural no município.

Em relação às condições de trabalho e renda, os entrevistados referem que há uma discrepância entre a oferta de oportunidades de trabalho e a pouca qualificação da população local. A maior dificuldade é o acesso a cursos profissionalizantes, sendo recente a expansão de cursos técnicos e de nível superior mais acessíveis aos moradores do município.

$\mathrm{Na}$ economia predomina o setor industrial e agropecuário, tendo destaque o ramo noveleiro e de eletroeletrônicos. Registrase a expansão da área urbana, por meio do aumento significativo da construção de imóveis nessa área, já a agricultura movimenta cerca de 30\% da economia (PINHALZINHO, [S.D.]).

\section{Serviços de Saúde, Ambientais e Sociais}

Em relação aos serviços de saúde, a abordagem dos profissionais e da comunidade ainda é centrada no modelo biomédico. 20\% das lideranças entrevistadas avaliam que esses serviços não resolvem os problemas e precisam melhorar em relação ao atendimento. Para alguns dos entrevistados, faltam especialidades médicas e a própria população centraliza o atendimento no médico, com pouco reconhecimento sobre o potencial de outros profissionais da saúde na resolução 

diminuição do número de internações hospitalares da população residente no município de 7,27\% em 2000 para 5,73\% em 2009 e o aumento dos atendimentos ambulatoriais de baixa, média e alta complexidade de 7,08 procedimentos por habitante em 2000 para 24,02 em 2009 (BRASIL, 2010).

Uma maior consciência da comunidade sobre os potenciais da atenção integral à saúde, sob coordenação da atenção básica, pode facilitar que esta assuma sua corresponsabilidade de forma mais ativa, o que requer dos profissionais de saúde práticas mais dialógicas com vistas ao aumento da autonomia e do poder efetivo dos sujeitos para refletir, questionar, decidir e agir (HAESER; BÜCHELE; BRZOZOWSKI, 2012).

$\mathrm{O}$ quinto campo de atuação descrito na Carta de Ottawa traz a reorientação dos serviços de saúde, os quais devem ter uma postura que ampare "as necessidades individuais e comunitárias para uma vida mais saudável, abrindo canais entre o setor saúde e os setores sociais, políticos, econômicos e ambientais" (BRASIL, 2002 , p. 24). Nesse sentido, percebe-se a inserção, ainda pontual, de profissionais de saúde nos grupos coordenados pela assistência social, sem iniciativa, contudo, de planejamento conjunto de ações de enfrentamento frente as condições de risco e vulnerabilidade no território.

Azevedo, Pelicioni e Westphal (2012) destacam a intersetorialidade como resultado do movimento dialógico de diferentes instituições em prol de parcerias, visando ações conjuntas para alcançar objetivos e metas comuns. Apesar da diversidade de atuação, os diferentes setores envolvidos constituem certa unidade na busca de vínculos que oportunizem a superação da fragmentação e da especialização vigente.

Quanto aos estabelecimentos educacionais, o destaque é a melhoria do acesso das crianças e adolescentes da área rural à escola, com transporte disponibilizado pelo município. No entanto, fatores como a longa distância percorrida diariamente para chegar a escola e a diferença de acesso a outras oportunidades de socialização e desenvolvimento cultural têm acirrado situações de iniquidade, produzindo rupturas na formação da identidade e na construção do sentimento de pertencimento dessas crianças e adolescentes em relação à sua identificação com a comunidade em que residem. Nas dinâmicas realizadas na escola percebeuse, em diferentes situações, discriminação por parte dos colegas 
residentes na área urbana sobre os relatos trazidos pelo grupo a respeito de sua realidade.

\section{Politicas de saúde e o compromisso em favor da vida}

O PlanejaSUS (BRASIL, 2009a) descreve os instrumentos de gestão que devem ser aplicados nos municípios não apenas para favorecer o gestor no planejamento, na implementação e na avaliação do processo, mas também para viabilizar a participação social, conforme preconizada na legislação. Nesse sentido, um dos instrumentos fundamentais da gestão do município é o Plano Municipal de Saúde, o qual estava em construção ainda em 2010, segundo informações da gestora de saúde. O Ministério da Saúde orienta que esse instrumento deve ser elaborado pelo gestor e aprovado pelo conselho municipal de saúde ainda no primeiro ano de governo (nesse caso em 2009), sendo base para orientar a implementação e avaliação de todas as ações no município (BRASIL, 2009a).

Em relação ao Conselho Municipal de Saúde, responsável pela aprovação do plano de saúde e pelo exercício do controle social sobre a execução da política de saúde no município, $82 \%$ das lideranças entrevistadas responderam que o conhecem e, destes, $56 \%$ relataram que já participaram ou estão participando do fórum; 73\% mencionaram que conhecem as funções do conselho, como expressa a fala de um líder comunitário:

Sei que todo conselho tem objetivo de resolver alguns problemas e levar a solução para a comunidade; ele funciona, mas depende das pessoas que coordenam - principalmente o gestor de saúde - envolver-se com o mesmo. O Conselho Municipal de Saúde tem grande poder de decisão; [...] tem a função de votar e aprovar coisas que são ou não são boas para o município, $[\ldots]$ mas falta envolvimento da comunidade.

Campos e colaboradores (apud AZEVEDO; PELICIONI; WESTPHAL, 2012, p. 1335) destacam a promoção da saúde como uma política que transita em todos os níveis de complexidade da gestão e da atenção em saúde, o que requer a mobilização dos usuários e profissionais da saúde como "protagonistas na organização do 'processo produtivo em saúde' envolvidos em um 'processo de construção compartilhada', a partir de atitudes dialógicas, flexíveis e generosas". 
A participação efetiva e concreta da comunidade na saúde requer aumento de seu poder técnico e político (empoderamento), fortalecendo sua capacidade de tomar decisões, escolher prioridades e elaborar estratégias com efeitos favoráveis à saúde (HAESER; BÜCHELE; BRZOZOWSKI, 2012).

Para além dos serviços de saúde, o Plano Municipal deve contemplar ações intersetoriais, em busca de superar a fragmentação das políticas públicas. As ações intersetoriais expressam a interação entre diversos setores no planejamento, execução e monitoramento de intervenções. A abordagem intersetorial voltada à melhoria das condições de vida amplia a compreensão sobre o termo saúde e passa a ser objetivo de todas as políticas públicas que influenciam a qualidade de vida das pessoas e coletividades (AZEVEDO; PELICIONI; WESTPHAL, 2012).

O sujeito social - gestor, técnico, profissional ou usuário mobilizado para decisões intersetoriais de promoção da saúde, deve estar aberto à revisão de posturas hierárquicas e centralizadoras, relativizando os interesses pessoais e a suposta segurança institucional relacionada a alguns formatos de cargos públicos. Uma incorporação sadia do sujeito nos processos decisórios se traduz em reflexões críticas sobre as próprias práticas, em posturas solidárias, comprometidas e generosas que visem ao bem estar comum, além de disponibilidade para o diálogo e para a mudança. (AZEVEDO; PELICIONI; WESTPHAL, 2012, p. 1352).

A articulação intersetorial como condição da Atenção Primária em Saúde (APS) abrangente é necessária para incidir sobre os determinantes sociais do processo saúde-doença e promover a saúde.

\section{Contribuições da estimativa rápida para a promoção da saúde junto à estratégia saúde da família}

Em estudo sobre a análise da realidade elaborada por equipes de saúde da família na grande Florianópolis/SC, Tesser et al (2011) identificaram que a coleta sistemática de dados pouco subsidiavam sua análise sobre a realidade da comunidade e, consequentemente, o planejamento de seu trabalho, incluindo a proposição de ações de promoção da saúde. Os registros realizados pelos ACS no cadastramento e recadastramento das famílias residentes no território adstrito 
a essas equipes assumiam, assim, caráter eminentemente burocrático, preenchendo o cumprimento de obrigações formais, gerando dados "para arquivo", que se transformam em "informação sem muito significado, [...] só uma coisa de preencher". (TESSER et al, 2011, p. 4302). Os autores do estudo consideram necessário maior estímulo e apoio institucional,

[...] para que os profissionais de saúde possam ressignificar seus processos de leitura e de análise da realidade, no sentido de revalorizar a potencialidade que o próprio trabalho e a imersão na realidade dos usuários têm de gerar propostas de ações de promoção da saúde, bem como de terapêutica e prevenção. (TESSER et al, 2011, p. 4305).

Entre outras competências, as equipes da ESF devem apropriar-se de ferramentas que viabilizem maior resolubilidade na atenção básica, com vistas ao cuidado integral à saúde. A utilização de diferentes tecnologias de cuidado individual e coletivo, a partir da identificação de riscos, necessidades e demandas em saúde e as oportunidades reveladas pelas iniciativas e pelos recursos existentes na comunidade devem estar voltadas à instituição "de uma clínica ampliada capaz de construir vínculos positivos e intervenções clínica e sanitariamente efetivas, na perspectiva de ampliação dos graus de autonomia dos indivíduos e grupos sociais" (BRASIL, 2011, p. 4).

O planejamento estratégico situacional pode contribuir de forma mais coerente nessa direção, enfatizando, ainda, a participação de todos os atores envolvidos na identificação dos problemas e na definição das prioridades de intervenção. Ao assumir um enfoque situacional, elegem-se como objeto de intervenção os problemas vivenciados e significados pela população, oferecendo subsídios mais viáveis de enfrentamento aos determinantes desses problemas (TESTA apud TEIXEIRA, 1993).

Técnicas participativas de diagnóstico, a exemplo da estimativa rápida, constituem-se possibilidades de maior envolvimento e motivação não apenas da equipe, incluindo nesse caso os ACS, mas também da comunidade, ampliando o potencial de corresponsabilização salientado na PNAB. A corresponsabilização é fortalecida pelas relações de confiança e afetividade, desenvolvidas a partir do vínculo estabelecido entre trabalhador da saúde, pessoas, famílias e grupos da comunidade 
que, por sua vez, é favorecido pelo processo de adstrição do território (BRASIL, 2011).

O Ministério da Saúde enfatiza que a adstrição do território permite

[...] o planejamento, a programação descentralizada e o desenvolvimento de ações setoriais e intersetoriais com impacto na situação, nos condicionantes e determinantes da saúde das coletividades que constituem aquele território sempre em consonância com o princípio da equidade. (BRASIL, 2011, p. 3).

Se considerarmos a complexidade do diagnóstico de saúde, coerente com o que o Art. $3^{\circ}$ da Lei 8.080 compreende como múltiplos condicionantes e determinantes da saúde (BRASIL, 1990), o setor saúde necessita aprender a dialogar de forma mais efetiva com os demais setores da política pública e com as organizações comunitárias, com vistas a concretizar os objetivos do SUS.

Aestimativa rápidaoportuniza,emumperíodocurto de tempo, definir principais problemas e potencialidades da comunidade, envolvendo diferentes sujeitos (gestores, profissionais e usuários) e incluindo no diagnóstico dados relevantes sobre condições de vida e saúde, referidas ao território adstrito. Isso favorece que sejam contempladas no processo de planejamento ações de parceria com outros setores governamentais e organizações não governamentais atuantes no território, viabilizando a consecução das diretrizes preconizadas pela Constituição da República Federativa do Brasil (BRASIL, 1988) para a organização e a implementação do cuidado, quais sejam: a descentralização, a atenção integral e a participação da comunidade.

\section{Considerações finais}

A estimativa rápida mostrou-se uma ferramenta adequada ao reconhecimento da realidade de acordo com as premissas do planejamento estratégico situacional. Por um lado ela promoveu maior interação entre equipe de saúde e a comunidade, oportunizando compartilhar saberes e informações, possibilitando incluir no diagnóstico da situação de saúde a perspectiva de diferentes atores sociais; por outro lado, promoveu a intersetorialidade, pois incluiu no processo atores de outros setores do município, como a educação e a assistência social. 
O diagnóstico revelou desafios, mas também muitas oportunidades no território de atuação da ESF. Na perspectiva da promoção da saúde, ressaltam-se os inúmeros grupos e lideranças ativas existentes no município, essenciais para prover apoio social no enfrentamento de situações adversas, bem como favorecer iniciativas construtivas em favor da coletividade. Isso favorece as equipes da ESF na implementação de atribuições preconizadas na atenção básica, tais como fortalecer a participação da comunidade e identificar parceiros para o desenvolvimento de ações de promoção da saúde. Facilita, ainda, que ambos assumam efetivamente a corresponsabilização na construção social da saúde, reconhecendo como foco de atuação compartilhada seus múltiplos determinantes e condicionantes.

\section{Referências}

ACÚRCIO, F. A.; SANTOS, M. A.; FERREIRA, S. M. G. Aplicação da técnica da estimativa rápida no processo de planejamento local. In: MENDES, E. V. (Org.). A organização da saúde no nível local. São Paulo: Hucitec, 1998. p. 87-110.

AZEVEDO, E.; PELICIONI, M. C. F.; WESTPHAL, M. F. Práticas intersetoriais nas políticas públicas de promoção de saúde. Physis Revista de Saúde Coletiva, v. 22, n. 4, p. 1333-56, 2012.

BORNSTEIN, V.J.; STOTZ, E. N. Concepções que integram a formação e o processo de trabalho dos agentes comunitários de saúde: uma revisão da literatura. Ciênc. saúde coletiva, v. 13, n. 1, p. 259-68, 2008.

BRASIL. Constituição (1988). Constituição da República Federativa do Brasil. Brasília, DF: Senado, 1988.

BRASIL. Lei № 8.080, de 19 setembro de 1990. Dispõe sobre as condições para a promoção, proteção e recuperação da saúde, a organização e o funcionamento dos serviços correspondentes e dá outras providências. Diário Oficial da União. Brasília, 1990.

BRASIL. Ministério da Saúde. Sistema de Planejamento do SUS (PlanejaSUS): uma construção coletiva - trajetória e orientações de operacionalização. Brasília: Ministério da Saúde/Organização PanAmericana da Saúde, 2009a.

BRASIL. Ministério da Saúde. DATASUS. Informações de saúde: Estatísticas vitais. Brasilia: Ministério da Saúde, 2010. Disponível em: <http:// 
BRASIL. Ministério da Saúde. Portaria No 2488/GM/MS, de 21 de outubro de 2011: Aprova a Política Nacional de Atenção Básica, estabelecendo a revisão de diretrizes e normas para a organização da Atenção Básica, para a Estratégia Saúde da Família (ESF) e o Programa de Agentes Comunitários de Saúde (PACS). Brasilia: Ministério da Saúde, 2011.

BRASIL. Ministério da Saúde. Portaria No 648/GM/MS, de 28 de março de 2006: Aprova a Política Nacional de Atenção Básica, estabelecendo a revisão de diretrizes e normas para a organização da Atenção Básica para o Programa Saúde da Família (PSF) e o Programa Agentes Comunitários de Saúde (PACS). Brasília, Diário Oficial da União no 61, de 29 de março de 2006, Seção 1, p. 71.

BRASIL. Ministério da Saúde. Secretaria de Políticas de Saúde. Projeto Promoção da Saúde. As Cartas da Promoção da Saúde. Brasília: Ministério da Saúde, 2002.

BRASIL. Ministério do Planejamento, Orçamento e Gestão. Instituto Brasileiro de Geografia e Estatística - IBGE. Diretoria de Pesquisas Coordenação de População e Indicadores Sociais. Indicadores Sociodemográficos e de Saúde no Brasil. Estudos e Pesquisas Informação Demográfica e Socioeconômica, número 25. Rio de Janeiro: IBGE, 2009b.

DI VILLAROSA, F. N. A. Estimativa Rápida e a divisão do território no Distrito Sanitário: Manual de Instruções. Série Desenvolvimento de Serviços de Saúde, n 11. Brasília: OPS-Representação do Brasil, 1993.

GONDIM, G. M. M.; MONKEN, M.; ROJAS, L. I. et al. O território da Saúde: a organização do sistema de saúde e a territorialização. In:MIRANDA A. C.; BARCELLOS C.; MOREIRA J. C. et al. (Orgs.). Território, ambiente e saúde. Rio de Janeiro: Editora Fiocruz, 2008. p. 237-55.

GURGEL, M. G. I., ALVES, M. D. S., MOURA, E. R. F. et al. Promoção da saúde no contexto da estratégia saúde da família. Esc Anna Nery, v. 15, n. 3, 201, p. 610-5.

HAESER L. M.; BÜCHELE, F.; BRZOZOWSKI, F. S. Considerações sobre a autonomia e a promoção da saúde. Physis Revista de Saúde Coletiva, v. 22, n. 2 , 2012, p. 605-20.

KURCGANT, P. Gerenciamento em enfermagem. Rio de Janeiro: Guanabara Koogan, 2005.

MENDES, E. V. Uma agenda para a saúde. São Paulo: Hucitec, 1996. 
MENDES, M. M. R.; LORO, F. C. C. Comunicação na velhice: subsídios da literatura (estudo piloto). In: Anais 8. Simpósio Brasileiro de Comunicação em Enfermagem, 2002, São Paulo, SP, Brasil [online]. Disponívelem: $<$ http://www.proceedings.scielo.br/scielo.php?script=sci_ arttext\&pid=MSC0000000052002000200045\&lng=pt\&nrm=iso > Acesso em 22 dez. 2013

PINHALZINHO. Prefeitura Municipal. Aqui é bom de viver. Pinhalzinho: Ancine [S.D.]. 1 DVD

TEIXEIRA, C.F.Planejamento e programação situacional em Distritos Sanitários: metodologia e organização. In: MENDES, E. V. (Org.) Distrito Sanitário: o processo social de mudança das práticas sanitárias do Sistema Único de Saúde. São Paulo: Hucitec, 1993. p. 237-65.

TESSER, C. D.; GARCIA, A. V.; VENDRUSCOLO, C. et al. Estratégia saúde da família e análise da realidade social: subsídios para políticas de promoção da saúde e educação permanente. Ciênc. saúde coletiva, v. 16, n. 11, p. 4295-306, 2011.

\title{
RAPID PARTICIPATIVE ESTIMATE AS A DIAGNOSTIC TOOL IN THE FAMILY HEALTH STRATEGY
}

\begin{abstract}
A rapid estimate is an appropriate tool of strategic situational planning for Family Health teams, enabling the analysis of the health situation of the territory, considering the perspective of different actors involved in the construction of the local reality. This study present data collected in the municipality Pinhalzinho, west of Santa Catarina - Brazil, through databases (SIAB), workshops with children and adolescents from local schools, groups of pregnant women, elderly, hypertensive and diabetics, as well as interviews with 11 leaders and field observation in order to identify problems and potential influencing local health. Community agents participated in the process through eight workshops, which resulted in the construction of physical maps comprising situations of interest for the diagnosis of health. The results were organized from the following dimensions: a) composition and capacity to act in the population; b) factors that influence the living conditions and health of the community; c) existence, coverage, access and acceptability of health, environmental and social services; d) enable public policies on health and social control. A rapid estimate promote greater community participation in planning, but also the intersetorial, creating greater dialogue between involved and encouraging the definition of actions and strategies for health promotion.
\end{abstract}

Keywords: Consumer Participation. Family Health Strategy. Health Promotion. Intersetorial Action. Diagnosis of Health Situation. 